\title{
Engagement in Games: Developing an Instrument to Measure Consumer Videogame Engagement and Its Validation
}

\author{
Amir Zaib Abbasi, ${ }^{1}$ Ding Hooi Ting, ${ }^{1}$ and Helmut Hlavacs ${ }^{2}$ \\ ${ }^{1}$ Department of Management and Humanities, Universiti Teknologi PETRONAS, Tronoh, Malaysia \\ ${ }^{2}$ Research Group Entertainment Computing, University of Vienna, Vienna, Austria
}

Correspondence should be addressed to Amir Zaib Abbasi; aamir.zaib.abbasi@gmail.com

Received 25 August 2016; Revised 22 December 2016; Accepted 10 January 2017; Published 31 January 2017

Academic Editor: Kok W. Wong

Copyright (C) 2017 Amir Zaib Abbasi et al. This is an open access article distributed under the Creative Commons Attribution License, which permits unrestricted use, distribution, and reproduction in any medium, provided the original work is properly cited.

\begin{abstract}
The aim of the study is to develop a new instrument to measure engagement in videogame play termed as consumer videogame engagement. The study followed the scale development procedure to develop an instrument to measure the construct of consumer videogame engagement. In this study, we collected the data in two different phases comprising study $1(n=136)$ and study 2 $(n=270)$. We employed SPSS 22.0 for exploratory factor analysis using study 1 respondents to explore the factors for consumer videogame engagement and reliability analysis. Results of EFA resulted with six-factor solution. We further used SmartPLS 3.0 software on study 2 respondents to further confirm the six-factor solution as reflective measurement model on the first-order level, and three second-order formative constructs on the second-order or higher-order level as formative measurement model. Results of the reflective measurement model and formative measurement model evidenced that consumer videogame engagement has strong psychometric properties and is a valid instrument to measure engagement in videogame play. Results also confirmed that consumer videogame engagement is a multidimensional construct as well as a reflective-formative construct. The study is unique in its investigation as it develops an instrument to measure engagement in videogame play which comprises the cognitive, affective, and behavioral dimensions.
\end{abstract}

\section{Introduction}

The popularity of videogame playing has increased significantly in the last decade $[1,2]$. The total consumer's expenditure on games industry has increased to $\$ 22.41$ billion in 2015 [3]. Videogame playing has the potential to attract millions of individuals worldwide to play [4] and it has become an essential part of our daily lives [5]. Videogame playing causes consumers to get addicted to a videogame [6] which finally leads people to engage in videogame play [7]. This is one of the key characteristics of videogames-it creates engagement in a videogame play [8]. Hence, engagement in videogames has become an important subject of study that needs considerable attention.
Engagement in videogames has been termed as a multidimensional concept $[9,10]$ which can be associated with a number of other notions, for instance, immersion $[4,7,11]$, flow [12], fun [13], enjoyment [14, 15], presence [16], motivations in videogame play [17], arousal [18], game engagement [19], and user engagement [20, 21].

However, several types of research have been conducted in videogame studies to explore and measure engagement in both the qualitative $[7,11,20]$ and quantitative manner $[4,5,19,21,22]$. Among all the studies, the study by Brown and Cairns [7] was the first study to qualitatively explore the concept of immersion and define a videogame player's experiences. The study results lead to the three main factors, engagement, engrossment, and total immersion, contributing 
to the construct of immersion. Another qualitative research by Ermi and Mäyrä [11] has studied the notion of immersion to recognize the essential features of game-play experience. The study came up with a new model of game-play experience called "SCI model," comprising the three dimensions sensory-immersion, challenge-based immersion, and imaginative immersion. We find that the results of Ermi and Mäyrä's study have similarities with the definition of immersion given by Brown and Cairns, for instance; imaginative immersion is similar to the state of engrossment and total immersion while challenge-based immersion and sensory-immersion refer to the dimension of engagement in Brown and Cairns' study.

Jennett et al. [4] expanded the study of [7] to measure the concept of immersion quantitatively. Their study developed an instrument to measure the subjective experience of videogame play based on the dimensions of gameflow, cognitive-absorption, and presence and named it gameexperience questionnaire or GEQ. Brockmyer et al. [19] have developed another scale named game engagement questionnaire or GEQ using a combination of four constructs, flow, presence, absorption, and immersion, to measure a player's engagement in videogames. Again, this study has used almost similar dimensions that were earlier used by [4]. In a similar vein, a recent study by Procci [23] has reviewed the model of the game engagement [19]. The author of the study discussed three dimensions such as flow, immersion, and presence of the game engagement questionnaire [19] to measure the subjective experience of videogame play. However, the absorption construct is more or less similar to the flow dimension, which makes the measurement less popular. According to Procci [23], a newly revised construct of game engagement comprises the dimensions flow, presence, involvement, and immersion that can be applied to examine the subjective experience of videogame play.

In previous literature, there is another available scale which was used to measure user experience in video games labeled user-engagement scale [24] that comprised of six factors-aesthetic appeal, novelty, focused attention, felt involvement, perceived usability, and endurability (i.e., a user's overall experience) [21]. The study applied the user engagement in videogame setting [24], but the structure of factors was not consistent with the original definition. The authors have also developed another scale to measure engagement in videogame learning with the combination of flow theory and cognitive load theory [22].

Hitherto, the current study has addressed past studies that have examined the past measurements of engagement scale and found that there is a critical need to develop and use engagement scale to examine player's engagement or subjective experience in videogame play. Critical review of prior studies indicates that few studies have used almost similar dimensions flow, presence, and absorption to examine the subjective experience of videogame play and measured player engagement in video games $[4,19,23]$. These studies have not properly conceptualized and operationalized the term engagement and immersion in their studies. Rather, these studies have just discussed that the constructs flow, presence, absorption, and immersion are related to immersion which can be used to measure the construct of immersion and game engagement. Besides, measurements were mainly focusing on quantifying the subjective experience of videogame play.

Secondly, several studies have stated that engagement in a videogame is a multidimensional construct $[5,9,10,22,24$, 25]. Among these studies, Cheng et al. [5] try to capture the meaning of engagement on a second-order construct when other studies did not analyze the concept of higher-order construct. The problem with the study by Cheng et al. [5] is that the authors have studied this construct as a reflectivereflective model. However, after critically reviewing the article, we believe that the authors have wrongly specified the construct of game immersion as a reflective-reflective model; rather, the game immersion construct seems to be a reflectiveformative model. This conclusion was drawn by reviewing the following studies $[26,27]$ which have discussed the important decision rules for specifying the construct as reflective or formative. The following studies have precisely discussed the decision rules $[26,27]$. The first rule is to look at the nature of the construct whether the latent construct is existing or formed. The second rule is to look at the direction of causality between the items and latent construct; if it is reflective, the causality is from construct to items, if it is formative then the causality is from items to the construct. The third rule is to look at the characteristics of items used to measure the construct such that if it is reflective, then the items should have a shared common theme, items are exchangeable, and deleting or adding an item does not change the meaning of the construct, whereas, if the construct is formative, items do not share a common theme, items are not replaceable, and deleting or adding an item changes the conceptual meaning of the construct.

This can be evidenced from the study [5] that, on the first order, all these dimensions of engagement (attraction, time investment, and usability), engrossment (emotional attachment, decreased perceptions), and total immersion (presence and empathy) are reflectively measured as these dimensions have causality from the construct to items and each dimension has a common-shared theme with interchangeable items, whereas, on the second-order constructs, these dimensions such as attraction, time investment, and usability (engagement), emotional attachment, decreased perceptions (engrossment), and presence and empathy (total immersion) should be measured formatively, where authors of the study [5] have neglected the importance of using formative construct, because engagement is collectively formed with the following dimensions (attraction, time investment, and usability), while engrossment is jointly made up by these dimensions (emotional attachment, decreased perceptions) and total immersion is together built with the following factors (presence and empathy). Besides, these dimensions have causality from the dimension itself to the higher level, dimensions do not share a common theme, dimensions are not interchangeable, and deleting any dimension can cause a variation on higher-order construct of game immersion. On this basis, game immersion construct should be considered a reflective-formative model than a reflective-reflective model.

Thirdly, past studies have given much importance to psychological dimensions immersion, flow, presence, involvement, and absorption to measure engagement in videogames 
$[4,12,19,22,23]$. However, these studies have not considered the importance of behavioral dimensions to measure a player's engagement in videogame play.

Hence, the current study considers the limitations of previous studies and intends to first conceptualize and operationalize the notion of engagement in videogame playing as consumer videogame engagement. Accordingly, the study aims to develop a new scale comprising both the psychological and behavioral dimensions to measure the construct of consumer videogame engagement. Moreover, the aim of the study is to validate the new scale consumer videogame engagement among the videogame consumers.

\section{Literature Review}

The present study reviews past researches that have mainly defined engagement and developed an instrument for measuring engagement in videogame studies.

\subsection{Definitions of Engagement and Its Related Constructs Used} in Videogames. Engagement has acquired a significant attention in several studies [19-22, 24]. Among these studies, the research by O'Brien and Toms [20] has qualitatively defined engagement as " $a$ value of user-experience that is dependent on numerous dimensions, comprising aesthetic appeal, novelty, usability of the system, the ability of the user to attend to and become involved in the experience and the user's overall evaluation of the salience of the experience." However, other studies have explained the notion of engagement with other theoretical constructs; for instance, flow, presence, immersion and absorption [19], presence, immersion, involvement and flow [23], cognitive and affective dimensions [22], focusedattention, perceived usability, aesthetics, and satisfaction [24] introduced a motivational model of videogame engagement that includes autonomy, competence, and relatedness [17].

Another definitional construct that has often used interchangeably with engagement is immersion [28]. Both engagement and immersion constructs have been investigated by these studies $[4,5,19,23]$ to examine the subjective experience as well as player's engagement in videogame play. Among these studies, the following researches [4, 19, 23] have used almost common dimensions of flow, presence, and immersion to quantify the subjective experience and engagement in videogame play.

\subsection{Existing Questionnaires on Immersion and Engagement in} Videogames. A large number of studies have put their efforts on developing and measuring the construct of immersion $[4,5]$ and engagement $[19,22,24]$. A study by Jennett et al. [4] was the first research to study the construct of immersion to describe the subjective experience in videogame play as game engagement. The construct of immersion [4] was developed with the help of three main theoretical constructs, flow, presence, and cognitive-absorption, which are commonly used to define engaging experiences. However, this study has ignored to differentiate these constructs flow and immersion in their study questionnaire labeled game immersion questionnaire.
However, a study by Brockmyer et al. [19] has addressed this gap by introducing the distinct position of these constructs flow and immersion in the study questionnaire called game engagement questionnaire. The study has used the term game engagement rather than game immersion to measure the subjective experience in videogame play. According to this study, game engagement is "a general sign of gameinvolvement." To measure game engagement in videogame play, the studyhas developed a game engagement questionnaire by considering such theoretical constructs absorption, presence, immersion, and flow. These theoretical constructs can be conceptualized as "a progression of ever deeperengagement in videogame-playing." Recently, a study by [23] has revisited the game engagement model in which the author has revised the game engagement model which was originally given by [19]. The author has identified that absorption is principally a flow. Therefore, it is better to exclude "absorption" from the game engagement model. Furthermore, the author has introduced the "involvement" dimension and termed it as R-GEM (revisited game engagement model).

Extant reviews of literature illustrate that few studies have developed a scale for measuring engagement through a user-engagement scale [24], or immersion by the game immersion questionnaire [5]. Among these studies, Cheng et al. [5] have developed a game immersion questionnaire by immersion theory [7]. According to these studies [5, 7], immersion comprises of the three phases-engagement, engrossment, and total immersion. The study by O'Brien and Toms [21] has applied the definition of user engagement [20] to operationalize and develop the construct of user engagement. The user-engagement scale was originally developed to measure engagement in an online shopping environment by [21]. Recently, this scale was also used in the context of a videogame by [24] who found that only the four factorsfocused-attention, perceived usability, aesthetics, and satisfaction have passed through the EFA test, while the remaining factors have been deleted. However, the factor structure of the user-engagement scale was not consistent with the original measurement scale proposed by [21] which comprised of six factors such as aesthetics, focused-attention, felt-involvement, novelty, endurability, and perceived usability. The same authors [22] have also measured engagement with a combination of cognitive load theory and flow theory.

To date, past studies have only considered psychological constructs to measure the subjective experience and player engagement in videogame play $[4,5,19,22,23]$. However, these studies are limited to measure the construct of game engagement with both psychological and behavioral dimensions. These studies $[4,19,22,23]$ have not properly conceptualized and operationalized the construct of game engagement in their studies, while some studies have wrongly specified the model $[5,24]$; for instance, according to Wiebe et al. [24], the user-engagement scale is a multidimensional construct, but they measured on a unidimensional level and authors have ignored investigating it on a multidimensional level or higher-order level. In a similar vein, another study by Cheng et al. [5] has also miss-specified the construct of 
immersion as a reflective-reflective model. Rather, the construct of immersion is a reflective-formative model and should be dealt with carefully.

This study considers the limitations of past studies and takes an opportunity to properly conceptualize and operationalize the construct of engagement in videogame play as consumer videogame engagement. Furthermore, the objective of this study is to validate the construct of consumer videogame engagement on a multidimensional level; it first measures the first-order construct as reflective measurement model, also known as Mode A type of analysis, and evaluates the second-order construct as formative measurement model called Mode B type of analysis in SEM-PLS.

\section{Conceptualization of Consumer Videogame Engagement}

This study aims to conceptualize the notion of engagement in videogames as consumer videogame engagement. This study follows the definition of engagement given by [29-31] to conceptualize the concept of consumer videogame engagement as "engagement is a multidimensional construct which is subject to a context-specific expression of relevant cognitive, emotional, and behavioral dimensions." Moreover, Hollebeek [31] has further added that engagement is a process which is revealed as a result of two-way communications between the engagement-subject (consumer/customer) and a particular engagement-object such as a product, service, or a brand, which leads to generating consumer engagement states (cognitive, affective, and behavioral). Following the above stated definition, this study conceptualizes consumer videogame engagement as "a psychological state that triggers due to twoway interactions between the consumer and videogame product, which generates different level of consumer engagement states (cognitive, affective and behavioral)" [32].

\section{Scale Development and Validation of Consumer Videogame Engagement}

This study adopts the scale development procedure suggested by $[33,34]$ to operationalize and develop a scale for the construct of consumer videogame engagement. The scale development process involves the four main steps as in the following part: step one is to generate items for samples, step two involves first-time data collection and instrumentpurification, and step three comprises second-time data collection and performs the reanalysis. Finally, step four is to determine the scale of consumer videogame engagement on multidimensional level and the following part explains the four steps.

\section{A Flow Chart of Scale Development Process [33, 34]}

Item generation:

(i) Specify domains of consumer videogame engagement

(ii) Literature review

(iii) Content validity
Data collection (Study 1) and purification of measures:

(i) Coefficient of alpha

(ii) Exploratory factor analysis

Data collection (Study 2) and reanalysis of measures

(i) Coefficient of alpha

(ii) Confirmatory factor analysis

(iii) Construct validity

\subsection{Step One: Item Generation}

4.1.1. Operationalization or Specifying Domains of the Construct "Consumer Videogame Engagement". According to the scale development procedure $[33,34]$, the research should be specific in defining the construct-what needs to be included or excluded in the construct. Accordingly, this study defines consumer videogame engagement as "a psychological state that triggers due to two-way interactions between the consumer and video-game product, which generates different level of consumer engagement states (cognitive, affective and behavioral)." This study is mainly interested in measuring consumer videogame engagement regarding consumer's cognitive, affective, and behavioral engagement in videogame playing.

Besides, Churchill Jr. [33] has suggested some techniques (literature review, experience-surveys, focus-groups, and interviews) that can be applied to generate initial scale items. This study applies an extensive literature review approach to get a list of scale items. According to the literature review process suggested by [33], it has been discussed that a study should clearly explain how the variable is defined and how many factors/dimensions it has.

Through conducting an in-depth literature review, this study concludes that consumer videogame engagement is a multidimensional construct that comprises the three engagement states cognitive, affective, and behavioral. These three engagement states are further categorized into two subdimensions, for instance, conscious attention and absorption as dimensions of cognitive engagement, while dedication and enthusiasm represent affective engagement. Lastly, interaction and social interaction together refer to the state of behavioral engagement.

This study compiles the measurement scales as already reported in the literature which is specifically relevant to the following dimensions: conscious attention, absorption (cognitive engagement), dedication, enthusiasm (affective engagement), social interaction, and interaction (behavioral engagement). The items on the following dimensions such as conscious attention, six items (items 1 to 6) from [35], item 7 from [36], and item 8 from [24] are adapted. For the absorption dimension, this study adapts the scale from [37], whereas the measurement items for dedication are organized as item 1 from [38] and item 2 to item 7 from [39] and the scale items of enthusiasm are adapted from the study of [35]. However, the items of social connection such as item 1 to item 4 from [35] and remaining items 5, 6, and 7 from [40] are adapted. Finally, the scale items on the interaction dimension 
are adapted as item 1 to item 5 from [37]. In this phase, the study has generated 39 items that together measure the overall construct of consumer videogame engagement [32]. Next, this study performs the content validity on the generated 39 items.

4.1.2. Content Validity. According to [41], content validity is a subjective but systematic assessment of how sound the domain content of a construct is explained by its indicators. This study has invited 4 Ph.D. students and two experts specializing in Marketing to first evaluate the content of consumer videogame engagement and the relevance of 39 measurement items, second to assess the relevance of a dimension and its measuring items, and lastly to check the wording of the item content. Based on their comments and recommendations, this study revised and corrected certain items [32]. Following this procedure, the overall scale of consumer videogame engagement has satisfied the prerequisite of content validity.

4.2. Study One: First-Time Data Collection and Purification. To further purify the instrument of consumer videogame engagement, this study has collected data from teenage students and analyzes the data through internal consistency analysis and exploratory factor analysis. The reason behind the selection of teenage students is teenage students are considered the main population in studying videogameconsumption behavior, because they are not merely the firstgeneration of "home-based" console videogame-players such as "Nintendo, Sega-Genesis, and Sony-PlayStation," but they are yet labeled as enthusiastic videogame-players today [42].

This study has applied a multistage sampling technique to collect the study subjects. According to [43], multistage sampling technique involves the replication of two fundamental steps; step one is listing, and the other is sampling. Initially, this study has generated a list of four main states (Penang, Selangor, Johor, and Perak) of Malaysia. Next, it has randomly selected one state (Perak) from the list of four main states of Malaysia. From the Perak state, this study has obtained a list of intuitions both colleges and universities from the following source (http://www.malaysiauniversity.net). From this list, the study has randomly selected one public University and one private University. Within each selected university, the teenage students aged 16-19 of foundation/diploma and 1st year undergraduate programs were invited to participate in the survey. In the case of public university, the diploma students of these two faculties (faculty of architecture, planning and survey and faculty of arts and design) were randomly selected to participate in the study survey, while, in the private university, this study has randomly selected the foundation and 1st year undergraduate students of these faculties (IT and Engineering stream).

During the phase of data collection, the study questionnaire has been distributed and collected in the classroom setting under the presence of a lecturer. In total, this study has distributed 205 questionnaires in both universities, out of which 165 questionnaires were returned with a response rate of $0.81 \%$. Out of 165 questionnaires, this study left with 136 valid cases after deleting the missing values. The demographic
TABLE 1: Demographic profile of respondents.

\begin{tabular}{|c|c|c|}
\hline & $\begin{array}{c}\text { Sample } 1 \\
(N=136), \% \\
\text { EFA }\end{array}$ & $\begin{array}{c}\text { Sample } 2 \\
(N=270), \% \\
\text { CFA }\end{array}$ \\
\hline \multicolumn{3}{|l|}{ Gender } \\
\hline Male & 55.1 & 63.3 \\
\hline Female & 44.9 & 36.7 \\
\hline \multicolumn{3}{|l|}{ Age (years) } \\
\hline $15-16$ & 0 & 1.1 \\
\hline $17-18$ & 16.2 & 19.6 \\
\hline 19 & 83.8 & 79.3 \\
\hline \multicolumn{3}{|l|}{ Ethnicity } \\
\hline Malay & 88.2 & 38.1 \\
\hline Chinese & 10.3 & 50.0 \\
\hline Indian & 1.5 & 11.9 \\
\hline \multicolumn{3}{|l|}{ Education } \\
\hline Secondary school student & 3 & 11.5 \\
\hline Diploma/foundation student & 109 & 28.9 \\
\hline Fresh undergraduate student & 24 & 59.6 \\
\hline \multicolumn{3}{|l|}{ Frequency of videogame play } \\
\hline Everyday & 33.1 & 39.6 \\
\hline Once a week & 19.1 & 20.4 \\
\hline A few times a week & 47.8 & 40.0 \\
\hline \multicolumn{3}{|l|}{$\begin{array}{l}\text { Average daily hours of } \\
\text { videogame play }\end{array}$} \\
\hline 1-4hrs/daily & 66.9 & 71.5 \\
\hline Above $4-8$ hrs/daily & 30.1 & 24.1 \\
\hline Above 8-12 hrs/daily & 2.2 & 2.6 \\
\hline More than 12 hrs/daily & .7 & 1.9 \\
\hline \multicolumn{3}{|c|}{$\begin{array}{c}\text { Answers generated in multiple response setting (percent of cases } \\
\text { means each percentage is out of 100) }\end{array}$} \\
\hline \multicolumn{3}{|c|}{$\begin{array}{l}\text { Most genre of videogames } \\
\text { played }\end{array}$} \\
\hline Action & 68.4 & 64.4 \\
\hline Adventure & 64.0 & 60.4 \\
\hline Arcade & 39.7 & 30.7 \\
\hline Shooter & 58.1 & 54.8 \\
\hline Role-playing & 39.7 & 47.0 \\
\hline Fighting & 55.9 & 47.0 \\
\hline Strategy & 60.3 & 58.1 \\
\hline Sports game & 45.6 & 34.8 \\
\hline Racing & 60.3 & 45.2 \\
\hline Casual & 22.1 & 22.6 \\
\hline Children' entertainment & 14.0 & 11.1 \\
\hline Family entertainment & 22.8 & 14.8 \\
\hline Flight & 14.0 & 14.4 \\
\hline Other videogames/genre & 8.1 & 6.7 \\
\hline \multicolumn{3}{|l|}{$\begin{array}{l}\text { Most common platform for } \\
\text { videogame players }\end{array}$} \\
\hline Personal computer & 81.6 & 78.5 \\
\hline Dedicated gaming console & 43.4 & 23.7 \\
\hline Smartphone & 70.6 & 66.7 \\
\hline Wireless device & 20.6 & 22.6 \\
\hline Dedicated handheld device & 8.1 & 8.1 \\
\hline Others & .7 & 0 \\
\hline
\end{tabular}

profile of the respondents for data collection one (sample 1 $N=136$ ) and data collection two (sample $2 N=270$ ) is given in Table 1. 
TABLE 2: Exploratory factor analysis (sample $1 N=136$ ).

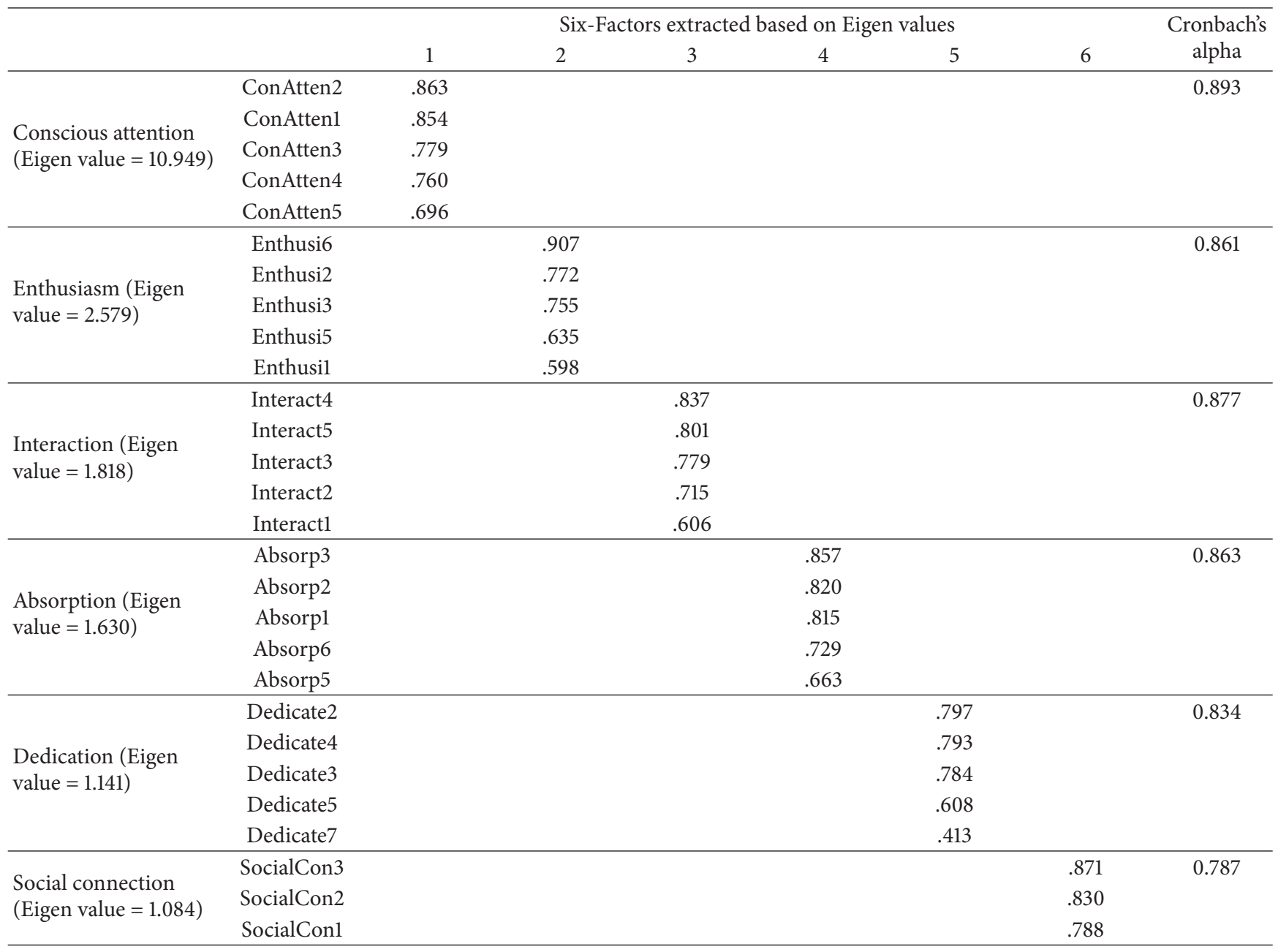

The next section has analyzed the collected data on the basis of internal consistency analysis also known as reliability analysis and exploratory factor analysis.

4.2.1. Purification: Exploratory Factor Analysis (EFA) and Reliability Analysis. The data were further analyzed through exploratory factor analysis using the promax rotation to drop the number of items and explore the factors for consumer videogame engagement. The items were dropped on having a loading lower than 0.40 on single factor as well as on their associated cross-loadings [44]. In total we had generated 39 items for consumer videogame engagement, but out of 39 items, we loaded 34 items to explore the factors for consumer videogame engagement. The remaining 5 items were used for redundancy analysis as discussed in the later stage and out of 5 items; only 3 items were better capturing the whole construct of consumer videogame engagement.

The result of factor analysis is shown in Table 2. Table 2 resulted with six-factor solution based on Eigen values as suggested by [45]. This study further examined the reliability of the construct which should be more than 0.70 as mentioned by [46] and Table 2 showed that all dimensions had reliability of more than .70 which means the construct met the criteria of reliability assessment.

4.3. Study Two: Second-Time Data Collection and Reanalysis of the Measurement Construct. Study two also followed the same procedure of multistage sampling technique. The only difference is that this study has extended the survey from two universities to 5 institutions. This time, the study has distributed around 365 questionnaires in five institutions, out of which the study has successfully collected 300 questionnaires with a response rate of $82 \%$. After treating the missing values, the study was left with 270 valid responses and the demographic details of the respondents were given in Table 1. In the next section, we analyzed the confirmatory factor analysis and other validity tests on using sample 2 comprising 270 respondents.

4.3.1. Analysis. SEM-PLS (structural equation modelingpartial least squares) was employed to validate the measurement construct of consumer videogame engagement because 
TABLE 3: Confirmatory factor analysis and construct validity (convergent and discriminant validity) Sample $2(N=270)$.

\begin{tabular}{|c|c|c|c|c|c|}
\hline \multirow{2}{*}{ Construct scale } & \multirow{2}{*}{ Item } & \multicolumn{2}{|c|}{ Convergent validity } & \multirow{2}{*}{ CR } & \multirow{2}{*}{ Cronbach's alpha } \\
\hline & & Loadings & AVE & & \\
\hline \multirow{5}{*}{ Conscious attention } & Con.Atten1 & 0.854 & 0.72 & 0.93 & 0.91 \\
\hline & Con.Atten2 & 0.864 & & & \\
\hline & Con.Atten3 & 0.841 & & & \\
\hline & Con.Atten 4 & 0.854 & & & \\
\hline & Con.Atten5 & 0.840 & & & \\
\hline \multirow{5}{*}{ Absorption } & Absorp1 & 0.735 & 0.61 & 0.89 & 0.84 \\
\hline & Absorp2 & 0.728 & & & \\
\hline & Absorp3 & 0.832 & & & \\
\hline & Absorp5 & 0.802 & & & \\
\hline & Absorp6 & 0.808 & & & \\
\hline \multirow{5}{*}{ Dedication } & Dedicate2 & 0.832 & 0.64 & 0.90 & 0.86 \\
\hline & Dedicate3 & 0.849 & & & \\
\hline & Dedicate 4 & 0.819 & & & \\
\hline & Dedicate 5 & 0.821 & & & \\
\hline & Dedicate7 & 0.678 & & & \\
\hline \multirow{5}{*}{ Enthusiasm } & Enthusil & 0.756 & 0.65 & 0.90 & 0.86 \\
\hline & Enthusi2 & 0.846 & & & \\
\hline & Enthusi3 & 0.837 & & & \\
\hline & Enthusi5 & 0.813 & & & \\
\hline & Enthusi6 & 0.768 & & & \\
\hline \multirow{3}{*}{ Social connection } & Social.Con1 & 0.895 & 0.75 & 0.90 & 0.84 \\
\hline & Social.Con2 & 0.850 & & & \\
\hline & Social.Con3 & 0.857 & & & \\
\hline \multirow{5}{*}{ Interaction } & Interact1 & 0.819 & 0.68 & 0.91 & 0.88 \\
\hline & Interact2 & 0.808 & & & \\
\hline & Interact3 & 0.873 & & & \\
\hline & Interact 4 & 0.821 & & & \\
\hline & Interact5 & 0.792 & & & \\
\hline
\end{tabular}

consumer videogame engagement has both reflective and formative constructs [47]. This study has further employed SEM-PLS, which is currently used by many academics as it delivers a robust way to analyze the survey data [47]. Moreover, PLS has less restriction on sample size and data distribution, and it has the potential to measure the measurement model and structural model simultaneously [39]. The current study is mainly on scale validation. Therefore, structural model assessment is not applicable. The next section follows the measurement model.

4.3.2. Measurement Model. The construct of consumer videogame engagement is a multidimensional construct, which comprises the reflective-formative model. For a reflective measurement model, this study involves the estimation of internal consistency, convergent validity, and discriminant validity, whereas the evaluation of the measurement model of a formative construct follows different guidelines such as testing of multicollinearity, indicator weights, and redundancy analysis.
4.3.3. Evaluation of Reflective Measurement Model. Initially, a reflective measurement model was assessed for its convergent validity. Convergent validity was measured through factor loadings greater than 0.60 [48], composite reliability desirable at 0.70 , and average variance extracted that should be at least $0.50[41,49]$. The results in Table 3 claimed that all standards of convergent validity were met, whereas factor loadings were more than 0.60 , and composite reliability and Cronbach's alpha were greater than 0.70 , while AVE of all constructs exceeded the critical value 0.50 .

4.3.4. Discriminant Validity. Discriminant validity of reflective constructs was evaluated through newly introduced method called Heterotrait-Monotrait ratio of correlations [50]. The criterion to evaluate the discriminant validity is to assess the HTMT value; if it exceeds the HTMT value of 0.85 , then there is an issue of discriminant validity. According to Table 4, all the values passed the critical value of HTMT.85 which represents that discriminant validity is not a problem. 
TABLE 4: Discriminant validity Heterotrait-Monotrait (HTMT).

\begin{tabular}{|c|c|c|c|c|c|c|}
\hline & Absorption & Conscious attention & Dedication & Enthusiasm & Interaction & Social connection \\
\hline \multicolumn{7}{|l|}{ Absorption } \\
\hline Conscious attention & 0.67 & & & & & \\
\hline Dedication & 0.70 & 0.83 & & & & \\
\hline Enthusiasm & 0.81 & 0.71 & 0.74 & & & \\
\hline Interaction & 0.57 & 0.60 & 0.64 & 0.66 & & \\
\hline Social connection & 0.41 & 0.57 & 0.49 & 0.55 & 0.62 & \\
\hline
\end{tabular}

TABLE 5: Evaluation of formative constructs (full collinearity, weights, and T-value).

\begin{tabular}{|c|c|c|c|c|c|c|}
\hline Construct & Measurement model & Items & Weights & VIF & $T$-values & $P$ values \\
\hline \multirow[t]{2}{*}{ Cognitive engagement } & Formative & ConsAtten & 0.72 & 1.54 & 7.33 & 0.00 \\
\hline & & Absorption & 0.39 & 1.54 & 3.24 & 0.00 \\
\hline \multirow[t]{2}{*}{ Affective engagement } & Formative & Dedication & 0.48 & 1.671 & 4.90 & 0.00 \\
\hline & & Enthusiasm & 0.62 & 1.671 & 6.35 & 0.00 \\
\hline \multirow[t]{2}{*}{ Behavioral engagement } & Formative & Interaction & 0.76 & 1.399 & 10.86 & 0.00 \\
\hline & & Social connection & 0.36 & 1.399 & 4.16 & 0.00 \\
\hline
\end{tabular}

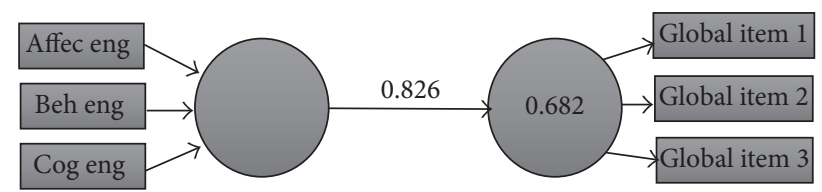

FIGURE 1: The result of redundancy analysis/convergent validity is shown.

4.3.5. Evaluation of Formative Measurement Model. This study has assessed the three criteria for the evaluation of formative measurement model as suggested by [41]. The first criterion to assess the convergent validity is the redundancy analysis. To do redundancy analysis in this study, the formative constructs were loaded on an exogenous latent variable named "consumer videogame engagement" predicting endogenous latent-variable labeled "global measure" that comprises the three reflective items. The path coefficient between the two constructs is desired to be at least 0.80 as recommended by [41]. The results indicated that the path coefficient between consumer videogame engagement and global measure was 0.826 as shown in Figure 1, which was higher than the threshold value and thus demonstrating that the formative constructs have achieved the convergent validity.

Additionally, this study has assessed the second criterion to check the collinearity issues in the formative constructs. The study found that there is no multicollinearity issue because of all values as shown in Table 3 are below the threshold value of 5 as suggested by [41]. The third criterion is to check the significance of the indicator weights on the designated second-order formative constructs. If indicator weights are significant then formative construct fulfills the criteria to be in the construct [41] and this study assessed the significance of indicator weights as shown in Table 5 and found that all formative constructs were highly significant at 0.00 level.

\section{Discussion}

The present study discussed the concept of engagement in videogame studies and also debated on previous scales of engagement in videogame literature. We reviewed each of the engagement scale and discussed its limitations and issues. We also discussed that previous measurements were limited to measure engagement from these theoretical constructs immersion, flow, presence, involvement, and absorption, which were more related to player's psychological engagement (cognitive engagement) in videogame playing. However, another psychological dimension such as affective engagement and behavioral dimension was largely ignored to apply in examining the player's engagement in digital game playing. Therefore, we took this opportunity to develop a new scale coined as consumer videogame engagement that had both psychological (cognitive and affective) and behavioral dimensions. To develop a scale for consumer videogame engagement, we applied the definition of consumer engagement that is generally defined as follows: engagement is a multidimensional construct which is subject to a context-specific expression of relevant cognitive, emotional, and behavioral dimensions. So, we adapted this definition in videogame context and defined the construct of consumer videogame engagement as it is a psychological state that triggers due to two-way interactions 
between the consumer and videogame product, which generates different level of consumer engagement states (cognitive, affective, and behavioral). On the basis of consumer videogame engagement definition, we applied the scale development approach to develop a scale for consumer videogame engagement. During the validation process, we extracted a six-factor solution for consumer videogame engagement. We further analyzed the six-factor solution for the evaluation for reflective measurement model and then, we also assessed the six factors on their designated second-order construct such as cognitive, affective, and behavioral engagement for the evaluation of formative measurement model on second-order or higher-order level. We found that consumer videogame engagement is a multidimensional and valid source for capturing player's engagement in terms of both psychological (cognitive and affective engagement) and behavioral engagement. The newly developed and validated scale provides a better tool to assess engagement in videogame playing as it covers three aspects of player's engagement in game playing such as player's cognitive, affective, and behavioral engagement.

This study has several contributions and enhanced the studies of $[4,5,19,22-24]$ which have been particularly conducted on engagement in videogame studies. For instance, this research is first among videogame studies that have considered both psychological and behavioral dimensions to measure the construct of consumer videogame engagement. Secondly, the construct of consumer videogame engagement has been properly conceptualized as a multidimensional construct comprising cognitive, affective, and behavioral dimensions and accordingly developed a scale for measuring consumer videogame engagement. Thirdly, the scale of consumer videogame engagement has been validated as a reflective-formative model such as being reflective on the first-order and formative on the second-order. The results of the study have met both the criteria that have been suggested for the assessment of reflective and formative measurement model.

This study first conceptualized the definition of consumer videogame engagement and developed the scale for consumer videogame engagement. The data were collected in two phases. EFA and CFA were conducted to validate the scale of consumer videogame engagement. We further analyzed the consumer videogame engagement on the multidimensional level and results showed that consumer videogame engagement is a multidimensional and a reflective-formative construct.

\section{Competing Interests}

The authors declare that they have no competing interests.

\section{References}

[1] A. Z. Abbasi, D. H. Ting, and H. Hlavacs, "Proposing a new conceptual model predicting consumer videogame engagement triggered through playful-consumption experiences," in Entertainment Computing-ICEC 2016: 15th IFIP TC 14 International
Conference, Vienna, Austria, September 28-30, 2016, Proceedings, vol. 9926 of Lecture Notes in Computer Science, pp. 126-134, Springer, Berlin, Germany, 2016.

[2] J. Takatalo, J. Häkkinen, J. Kaistinen, and G. Nyman, "User experience in digital games: differences between laboratory and home," Simulation \& Gaming, vol. 42, no. 5, pp. 656-673, 2011.

[3] Entertainment Software Association, Essential Facts about the Computer and Video Game Industry, Entertainment Software Association, Washington, DC, USA, 2015.

[4] C. Jennett, A. L. Cox, P. Cairns et al., "Measuring and defining the experience of immersion in games," International Journal of Human-Computer Studies, vol. 66, no. 9, pp. 641-661, 2008.

[5] M.-T. Cheng, H.-C. She, and L. A. Annetta, "Game immersion experience: its hierarchical structure and impact on game-based science learning," Journal of Computer Assisted Learning, vol. 31, no. 3, pp. 232-253, 2015.

[6] S. Rigby and R. M. Ryan, Glued to Games: How Video Games Draw Us in and Hold Us Spellbound: How Video Games Draw Us in and Hold Us Spellbound, ABC-CLIO, 2011.

[7] E. Brown and P. Cairns, "A grounded investigation of game immersion," in Proceedings of the Conference on Human Factors in Computing Systems (CHI '04), pp. 1297-1300, Vienna, Austria, April 2004.

[8] N. Whitton, "Game engagement theory and adult learning," Simulation \& Gaming, vol. 42, no. 5, pp. 596-609, 2011.

[9] M. Filsecker and M. Kerres, "Engagement as a volitional construct: a framework for evidence-based research on educational games," Simulation \& Gaming, vol. 45, pp. 450-470, 2014.

[10] H. Schonau-Fog and T. Bjorner, "'Sure, I would like to continue’: a method for mapping the experience of engagement in video games," Bulletin of Science, Technology \& Society, vol. 32, no. 5, pp. 405-412, 2012.

[11] L. Ermi and F. Mäyrä, "Fundamental components of the gameplay experience: analysing immersion," in Worlds in Play: International Perspectives on Digital Games Research, vol. 37, p. 2, 2005.

[12] J. Chen, "Flow in games (and everything else)," Communications of the ACM, vol. 50, no. 4, pp. 31-34, 2007.

[13] R. Koster, Theory of Fun for Game Design, O'Reilly Media, Sebastopol, Calif, USA, 2013.

[14] D. K. Mayes and J. E. Cotton, "Measuring engagement in video games: a questionnaire," in Proceedings of the 45th Annual Meeting of Human Factors and Ergonomics Society, pp. 692-696, Minneapolis, Minn, USA, October 2001.

[15] W. IJsselsteijn, W. Van Den, C. Hoogen et al., "Measuring the experience of digital game enjoyment," in Proceedings of the 6th International Conference on Methods and Techniques in Behavioral Research, Measuring Behavior, pp. 88-89, Maastricht, the Netherlands, August 2008.

[16] A. McMahan, "Immersion, engagement and presence," The Video Game Theory Reader, vol. 67, p. 86, 2003.

[17] A. K. Przybylski, C. S. Rigby, and R. M. Ryan, "A motivational model of video game engagement," Review of General Psychology, vol. 14, no. 2, pp. 154-166, 2010.

[18] N. Ravaja, T. Saari, M. Salminen, J. Laarni, and K. Kallinen, "Phasic emotional reactions to video game events: a psychophysiological investigation," Media Psychology, vol. 8, no. 4, pp. 343-367, 2006.

[19] J. H. Brockmyer, C. M. Fox, K. A. Curtiss, E. McBroom, K. M. Burkhart, and J. N. Pidruzny, "The development of the Game 
Engagement Questionnaire: a measure of engagement in video game-playing," Journal of Experimental Social Psychology, vol. 45, no. 4, pp. 624-634, 2009.

[20] H. L. O'Brien and E. G. Toms, "What is user engagement? A conceptual framework for defining user engagement with technology," Journal of the American Society for Information Science and Technology, vol. 59, no. 6, pp. 938-955, 2008.

[21] H. L. O'Brien and E. G. Toms, “The development and evaluation of a survey to measure user engagement," Journal of the American Society for Information Science and Technology, vol. 61, no. 1, pp. 50-69, 2010.

[22] D. Sharek and E. Wiebe, "Measuring video game engagement through the cognitive and affective dimensions," Simulation \& Gaming, vol. 45, pp. 569-592, 2014.

[23] K. C. Procci, The subjective gameplay experience: an examination of the revised game engagement model [Ph.D. thesis], University of Central Florida Orlando, Orlando, Fla, USA, 2015.

[24] E. N. Wiebe, A. Lamb, M. Hardy, and D. Sharek, "Measuring engagement in video game-based environments: investigation of the user engagement scale," Computers in Human Behavior, vol. 32, pp. 123-132, 2014.

[25] C. Silpasuwanchai, X. Ma, H. Shigemasu, and X. Ren, "Developing a comprehensive engagement framework of gamification for reflective learning," in Proceedings of the 11th ACM SIGCHI Conference on Designing Interactive Systems (DIS '16), pp. 459472, ACM, Brisbane, Australia, June 2016.

[26] T. Coltman, T. M. Devinney, D. F. Midgley, and S. Venaik, "Formative versus reflective measurement models: two applications of formative measurement," Journal of Business Research, vol. 61, no. 12, pp. 1250-1262, 2008.

[27] S. Petter, D. Straub, and A. Rai, "Specifying formative constructs in information systems research," MIS Quarterly, vol. 31, no. 4, pp. 623-656, 2007.

[28] G. Hookham, K. Nesbitt, and F. Kay-Lambkin, "Comparing usability and engagement between a serious game and a traditional online program," in Proceedings of the Australasian Computer Science Week Multiconference (ACSW '16), Canberra, Australia, February 2016.

[29] R. J. Brodie, L. D. Hollebeek, B. Jurić, and A. Ilić, "Customer engagement: conceptual domain, fundamental propositions, and implications for research," Journal of Service Research, vol. 14, no. 3, pp. 252-271, 2011.

[30] R. J. Brodie, A. Ilic, B. Juric, and L. Hollebeek, "Consumer engagement in a virtual brand community: an exploratory analysis," Journal of Business Research, vol. 66, no. 1, pp. 105-114, 2013.

[31] L. D. Hollebeek, "Demystifying customer brand engagement: exploring the loyalty nexus," Journal of Marketing Management, vol. 27, no. 7-8, pp. 785-807, 2011.

[32] A. Z. Abbasi, D. H. Ting, and H. Hlavacs, "A revisit of the measurements on engagement in videogames: a new scale development," in Proceedings of the International Conference on Entertainment Computing, pp. 247-252, Vienna, Austria, September 2016.

[33] G. A. Churchill Jr., "A paradigm for developing better measures of marketing constructs," Journal of Marketing Research, vol. 16, no. 1, pp. 64-73, 1979.

[34] S.-H. Tsaur, C.-H. Yen, and Y.-T. Yan, "Destination brand identity: scale development and validation," Asia Pacific Journal of Tourism Research, pp. 1-14, 2016.
[35] S. D. Vivek, S. E. Beatty, V. Dalela, and R. M. Morgan, "A generalized multidimensional scale for measuring customer engagement," The Journal of Marketing Theory and Practice, vol. 22, no. 4, pp. 401-420, 2014.

[36] H. Qin, P.-L. P. Rau, and G. Salvendy, "Measuring player immersion in the computer game narrative," International Journal of Human-Computer Interaction, vol. 25, no. 2, pp. 107-133, 2009.

[37] K. K. F. So, C. King, and B. Sparks, "Customer engagement with tourism brands: scale development and validation," Journal of Hospitality \& Tourism Research, vol. 38, no. 3, pp. 304-329, 2014.

[38] W. B. Schaufeli, M. Salanova, V. González-romá, and A. B. Bakker, "The measurement of engagement and burnout: a two sample confirmatory factor analytic approach," Journal of Happiness Studies, vol. 3, no. 1, pp. 71-92, 2002.

[39] C. M. K. Cheung, X.-L. Shen, Z. W. Y. Lee, and T. K. H. Chan, "Promoting sales of online games through customer engagement," Electronic Commerce Research and Applications, vol. 14, no. 4, pp. 241-250, 2015.

[40] E. Kemp, "Engaging consumers in esthetic offerings: conceptualizing and developing a measure for arts engagement," International Journal of Nonprofit and Voluntary Sector Marketing, vol. 20, no. 2, pp. 137-148, 2015.

[41] J. Hair, G. T. Hult, C. M. Ringle, and M. Sarstedt, A Primer on Partial Least Squares Structural Equation Modeling (PLS-SEM), Sage, Thousand Oaks, Calif, USA, 2013.

[42] D. Lee and R. LaRose, "A socio-cognitive model of video game usage," Journal of Broadcasting and Electronic Media, vol. 51, no. 4, pp. 632-650, 2007.

[43] A. S. Acharya, A. Prakash, P. Saxena, and A. Nigam, "Sampling: why and how of it," 2013.

[44] J. K. Ford, R. C. Maccallum, and M. Tait, "The application of exploratory factor analysis in applied psychology: a critical review and analysis," Personnel Psychology, vol. 39, no. 2, pp. 291314, 1986.

[45] H. F. Kaiser, "The application of electronic computers to factor analysis," Educational and Psychological Measurement, vol. 20, no. 1, pp. 141-151, 1960.

[46] J. F. Hair, W. C. Black, B. J. Babin, R. E. Anderson, and R. L. Tatham, Multivariate Data Analysis, vol. 6, Prentice Hall, Upper Saddle River, NJ, USA, 2006.

[47] J. F. Hair, C. M. Ringle, and M. Sarstedt, "PLS-SEM: indeed a silver bullet," Journal of Marketing Theory and Practice, vol. 19, no. 2, pp. 139-152, 2011.

[48] W. W. Chin, "How to write up and report PLS analyses," in Handbook of Partial Least Squares, pp. 655-690, Springer, 2010.

[49] C. Fornell and D. F. Larcker, "Evaluating structural equation models with unobservable variables and measurement error," Journal of Marketing Research, vol. 18, no. 1, pp. 39-50, 1981.

[50] J. Henseler, C. M. Ringle, and M. Sarstedt, "A new criterion for assessing discriminant validity in variance-based structural equation modeling," Journal of the Academy of Marketing Science, vol. 43, no. 1, pp. 115-135, 2015. 


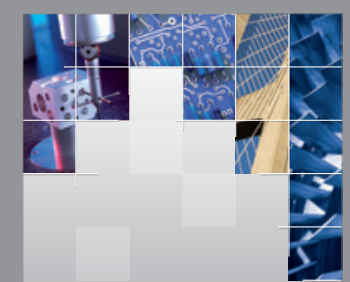

\section{Enfincering}
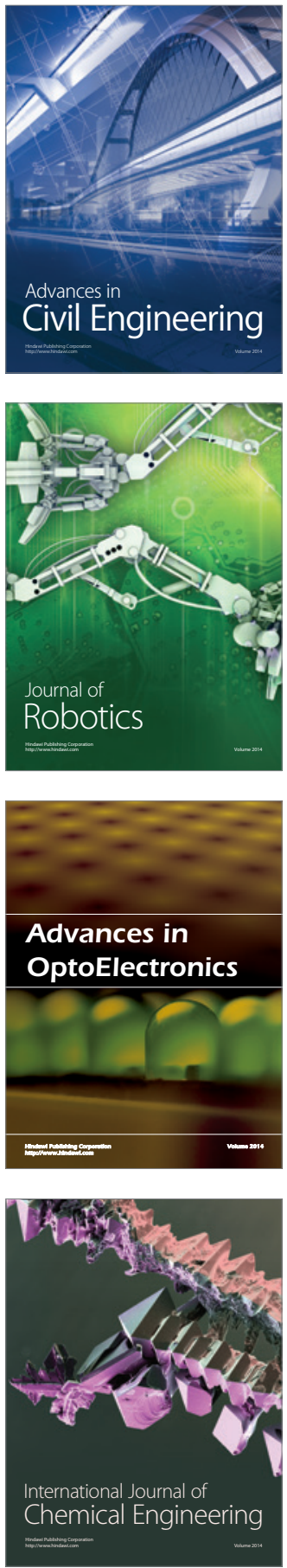

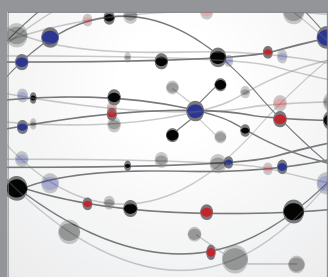

The Scientific World Journal

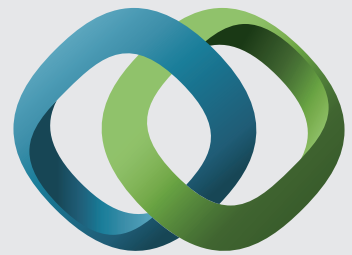

\section{Hindawi}

Submit your manuscripts at

https://www.hindawi.com
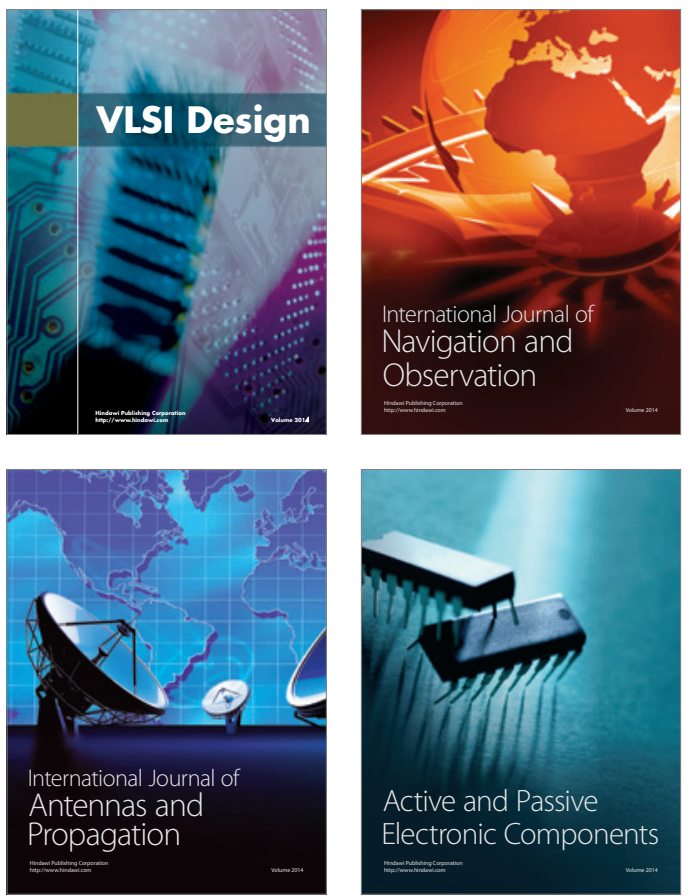
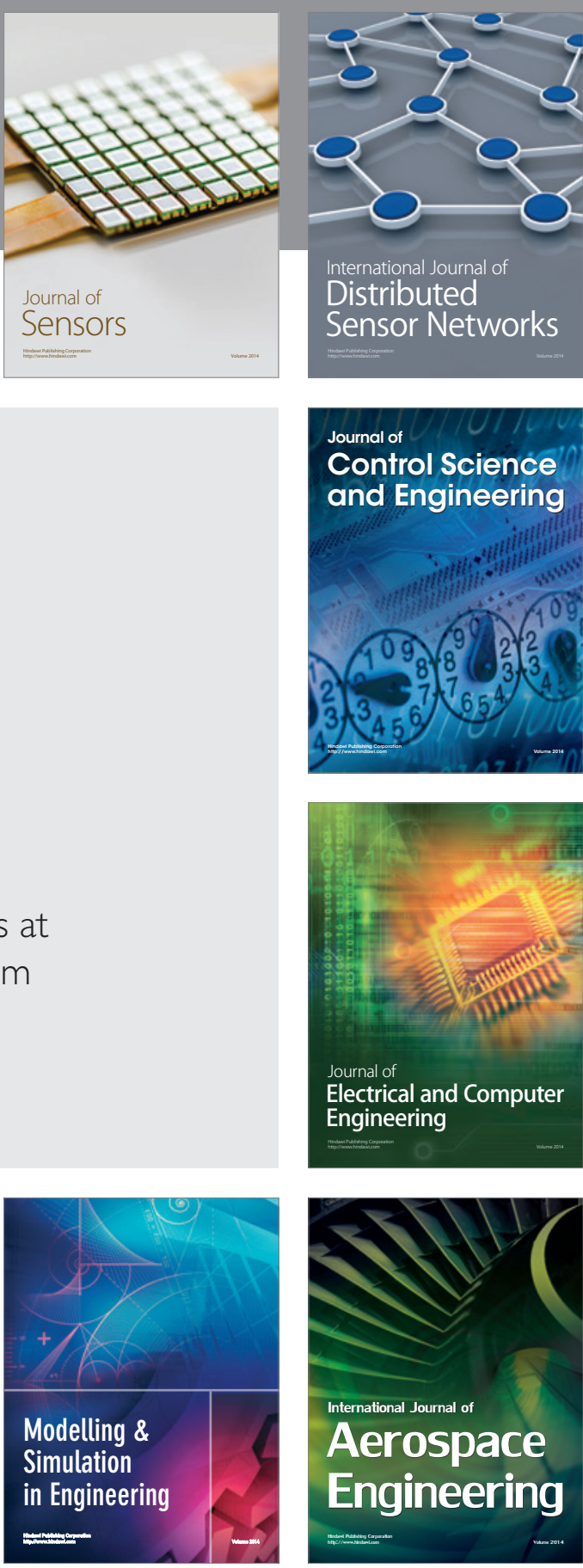

International Journal of

Distributed

Sensor Networks

$-$

Joumal of

Control Science

and Engineering
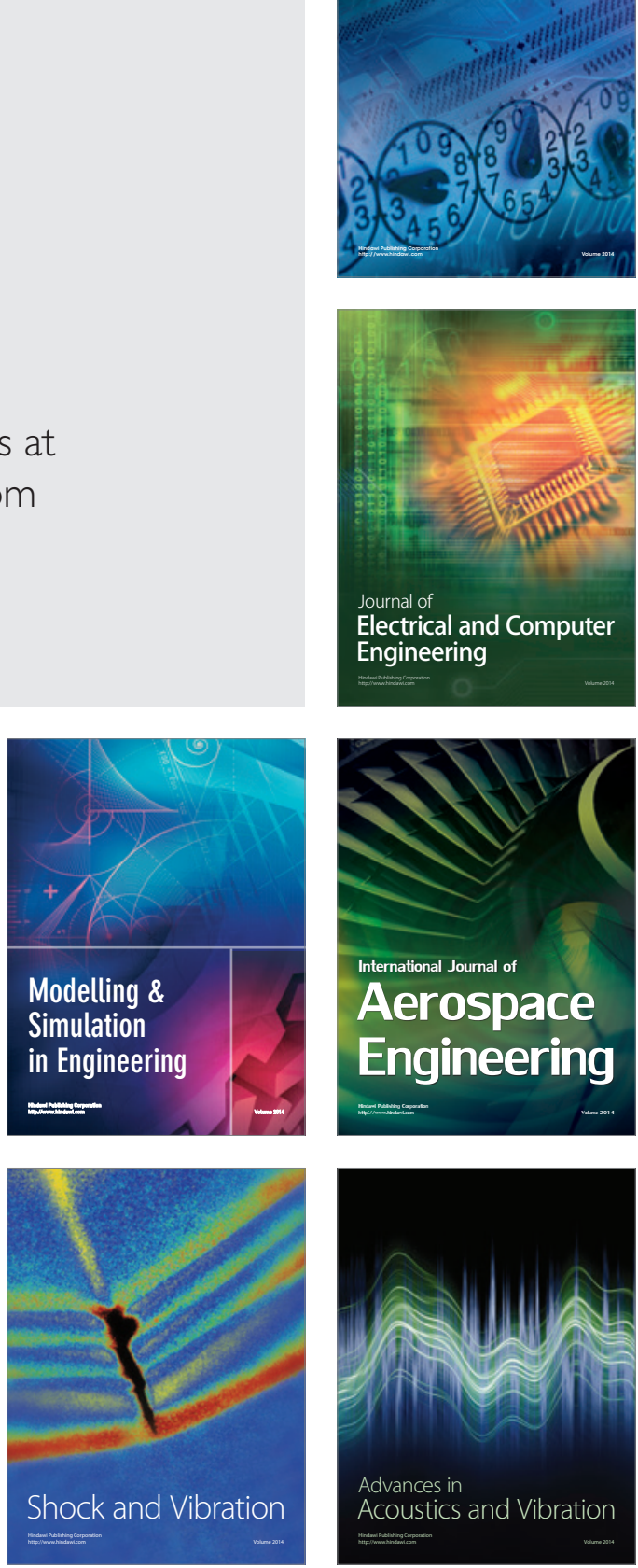